\title{
A PERSONALIZED TRAVEL RECOMMENDER SYSTEM USING FUZZY ANALYTIC HIERARCHY PROCESS
}

\author{
Ily Amalina Ahmad Sabri', Noor Maizura Mohamad Noor ${ }^{2}$, Noraida Haji Ali ${ }^{3}$ \& Fathilah Ismail ${ }^{4}$ \\ 1,2,3Faculty of Ocean Engineering Technology and Informatics, Universiti Malaysia Terengganu \\ ${ }^{4}$ Faculty of Business, Economics and Social Development, Universiti Malaysia Terengganu \\ (ilylina@umt.edu.my, maizura@umt.edu.my, aida@umt.edu.my, fathilah@umt.edu.my)
}

\begin{abstract}
Information and communication technologies have deep implications for the tourism industry. This combination of devices is being used extensively in an excessive variety of functions and numerous applications. On the other hand, tourism has become an extremely dynamic system. The globalisation enabled by technological development and budget travel has greatly increased competition. Decision support systems (DSS) can play an important role within organisations and assist people who manage tourist destinations. The main intention of this research paper is to see how to apply Decision Support Systems (DSS) to the tourism industry. It aims to establish a personalised interactive travel recommender system that can be shared and integrated easily in order to work as a proof of concept for the decision to provide the tourism sector with interactive decision support systems. Specifically, the study aims to achieve the following objectives which are to evaluate and measure criteria and alternatives to performance, to analyse the ranking of criteria and alternatives and to recommend tourist attractions in terms of islands, accommodation, activities and etc. based on the travellers' budget constraints. The evaluation module enables experts to evaluate and consider alternatives to the small islands to benchmark the islands' performance. An analysis module will provide reports for performance of criteria and alternatives based on a "Best Non-fuzzy Performance" basis. A risk analysis model for the travel recommender system using a fuzzy set approach has been proposed and incorporated into a Fuzzy Decision Support System (FDSS). This study presents fuzzy-AHP as a proposed method to apply to decision-making with social attributes. A web-based prototype Decision Support System (DSS) has been designed and developed in order to prove the objectives.
\end{abstract}

KEYWORDS: Decision Support System, Travel Recommender System, Fuzzy Analytic Hierarchy Process

\section{PURPOSE AND BACKGROUND}

Over the past few decades, numerous studies have been carried out on customer choice behaviours, particularly with regard to the destination choice model. However, only a few have attempted to integrate the use of web technology with traditional approaches to consumer choice behaviour.

With tourism expanding globally, the use of the Internet in tourism has become inevitable. This study presents an approach to the design of a destination choice model using a fuzzy multi-criteria decision support system that can be used by tourists to make choices on travel destinations.

Tourism decision support systems have been in existence for a few decades. During the early days, the focus was on developing better tourism data acquisition technology. They then attempt to integrate database management systems and artificial intelligence for more effective use and interpretation of available data to assist decision making in tourism. 
This study focuses on islands as a travel destination. The choice of location for travel is an important factor leading to the selection of the islands since it will determine how convenient it is to serve tourists and how many tourists are attracted to the place. There are six small islands in Terengganu and tourist have some characteristics that they consider when selecting an island to visit.

The evaluation process in the selection of islands needs to be evaluated by experts in order to provide tourists with the best recommendation. This research paper incorporates two major theoretic frameworks, namely the tourism decision support systems and web services, and applies them to evaluate and recommend the best island to tourist.

The tourism decision support system uses computers to analyze the performance of islands based on ten social attributes including attraction, accommodation, transportation, activity, entertainment, resident attitudes, environment, other facilities and souvenirs in order to enhance its accuracy.

This system also been developed to handle recommendations to tourists.

\section{METHODOLOGY}

The evaluation of a travel destination and the making of a recommendation is a wide-ranging problem with complex variables to consider. This study presents fuzzy-AHP as a proposed method to apply decision making with social attributes. This problem requires methods that can handle qualitative criteria's that are difficult to describe in crisp values. Fuzzy decision making is a powerful method to solve complex decision-making problems in a fuzzy environment.

This method can be applied with the problem of ranking and selection. In the real world, linguistic environmental factors are used by human beings in order to make decisions (Zadeh, 1975; Zadeh, 1983, 1987, 1997). Meanwhile, the original analytic hierarchy process (AHP) used in this proposal was first developed by Saaty (Saaty, 1977).

\section{FINDINGS}

The results from the software usability measurement inventory (SUMI) evaluations are presented in Table 1 and Table 2 in terms of the mean, upper and lower confidence intervals. These intervals are derived from the global usability scale and each of the five usability sub-scales which are efficiency, affect, helpfulness, controllability and learnability. The upper and lower confidence intervals represent the limits within which the theoretical true score falls $95 \%$ of the time for these respondents.

Table 1 and Table 2 show that, on the global scale, the SUMI evaluation indicates that the usability of the iTAS is within the lower and upper confidence intervals. The results showed consistent in terms of usability sub-scales.

Table 1: The Results from SUMI Questionnaires (Experts)

\begin{tabular}{cccc}
\hline Scale & Lower Confidence Interval & Mean & Upper Confidence Interval \\
\hline Global $\mathrm{n}=10$ & 2.78 & 3.30 & 3.81 \\
Helpfulness & 3.41 & 3.91 & 4.41 \\
Controllability & 2.96 & 3.47 & 3.97 \\
Learnability & 2.18 & 2.73 & 3.28 \\
Efficiency & 2.32 & 2.90 & 3.48 \\
Affect & 2.99 & 3.45 & 3.90 \\
\hline
\end{tabular}


Table 2: The Results from SUMI Questionnaires (Tourists)

\begin{tabular}{cccc}
\hline Scale & Lower Confidence Interval & Mean & Upper Confidence Interval \\
\hline Global $\mathrm{n}=60$ & 2.94 & 3.17 & 3.39 \\
Helpfulness & 3.70 & 3.89 & 4.08 \\
Controllability & 3.00 & 3.33 & 3.66 \\
Learnability & 2.37 & 2.60 & 2.82 \\
Efficiency & 2.42 & 2.62 & 2.83 \\
Affect & 3.19 & 3.39 & 3.58 \\
\hline
\end{tabular}

\section{CONCLUSION}

The findings in this research show that this study is consistent with the hypotheses made. All hypotheses made based on the five aspects of user satisfaction are consistent and therefore accepted to be true.

The iTAS is found to be helpful. The users feel in control over the iTAS. The iTAS is easy to learn even for novice users. On a global scale, experts, aspects of helpfulness and controllability have the highest mean scores compared to other aspects. This shows that the experts find that the iTAS is helpful and they are in control of the iTAS. Tourists find that the iTAS was helpful and easy to use but some modifications have to be focused on. Learnability and efficiency received the lowest mean as compared to the other aspects.

\section{CONTRIBUTION/PRACTICAL IMPLICATIONS}

The author's suggests improvements to the user interface with better functions and information to improve efficiency and learnability. The benefits of this are several orders of magnitude more for the tourist attractions and this will also affect consumer interest in being able to visit islands in Terengganu.

\section{REFERENCES}

Saaty, T. L. (1977). A scaling method for priorities in hierarchical structures. Journal of Mathematical Psychology, 15(3), 234-281.

Zadeh, L. A. (1975). The concept of a linguistic variable and its application to approximate reasoning. Information Science, 8(1), 199-249.

Zadeh, L. A. (1976). The linguistic approach and its application to decision analysis. Paper presented at the U.C. Ho, S.M. Kitter (Eds.), Proceeding of conference on Directions in Decentralized Control, Many people Optimization and Large-Scale Systems, Plenum Press, New York.

Zadeh, L. A. (1983). A computational approach to fuzzy quantifiers in natural languages. Computers \& Mathematics with Applications, 9(1), 149-184.

Zadeh, L. A. (1987). Mind over machine: The power of human intuition and expertise in the era of the computer. Hubert L. Dreyfus and Stuart E. Dreyfus. Published by: New York, The Free Press, 1986. Future Generation Computer Systems, 3(2), 149-151.

Zadeh, L. A. (1997). Toward a theory of fuzzy information granulation and its centrality in human reasoning and fuzzy logic. Fuzzy Sets and Systems, 90(2), 111-127. 